\title{
Design of Natural Fiber Composites Chemical Container Using Resin Flow Simulation of VARTML Process
}

\author{
Changduk Kong, Hyunbum Park, Haseung Lee, and Jounghwan Lee
}

\begin{abstract}
In this study, an investigation on mechanical properties of flax natural fiber composite is performed as a precedent study on the design of eco-friendly structure using flax natural fiber composite. The Vacuum Assisted Resin Transfer Molding-Light (VARTML) manufacturing method is adopted for manufacturing the flax fiber composite panel. The VARTML is a manufacturing process that the resin is injected into the dry layered -up fibers enclosed by a rigid mold tool under vacuum. In this work, the resin flow analysis of VARTM manufacturing method is performed. A series of flax composite panels are manufactured, and several kinds of specimens cut out from the panels are tested to obtain mechanical performance data. Based on this, structural design of chemical storage tank for agricultural vehicle was performed using flax/vinyl ester. After structural design and analysis, the resin flow analysis of VARTM manufacturing method was performed.
\end{abstract}

Index Terms-Mechanical properties, natural composite, resin flow analysis, structural design.

\section{INTRODUCTION}

Recently due to increasing interest in eco-friendly materials, studies on eco-friendly fiber obtained from nature have been actively conducted to the area of composite. Although the natural fiber has less strength than the high strength fiber such as the carbon fiber, it has similar strength to glass fiber. Accordingly, it can be applied as very advantageous composite when an appropriate resin has been selected.

For the purpose of applying eco-friendly material of aircraft doors or interiors, this study evaluates mechanical properties of natural fiber composites. The mechanical properties of several natural fibers are reviewed and compared to select a proper nature fiber for the target study structure. After reviewing several kinds of natural fibers, several resins to be applied to the selected natural fiber are reviewed through comparison of mechanical properties including strength, interaction with fiber, cost, etc. Finally the flax is selected as a natural fiber due to higher strength and better mechanical behaviors than other natural fibers, and the vinyl ester is selected as a resin due to lower cost, easier

Manuscript received December 31, 2013; revised March 25, 2014. This work was supported in part by the Gwangju Innopolis Global Collaboration and Howon University Research Funds

Hyunbum Park is with the Department of Defense \& Science Technology-Aeronautics, Howon University, Republic of Korea (e-mail: swordship@daum.net).

Changduk Kong and Haesung Lee are with the Department of Aerospace Engineering, Chosun University (e-mail: cdgong@chosun.ac.kr, imorger@nate.com).

Jounghwan Lee is with the Advanced Manufacturing Research Centre with Boeing, The University of Sheffield (e-mail: jhlee@kseauk.org). procurement and better treatment for the resin injection. For easy and fast production of the complicated configuration structure, the vacuum assisted resin transfer molding (VARTM) manufacturing method is selected. The flax/vinyl ester composite specimens are manufactured and tested to find the mechanical properties. Based on this, structural design of chemical storage tank for agricultural vehicle was performed using flax/vinyl ester. After structural design and analysis, the resin flow analysis of VARTM manufacturing method was performed.

\section{INVESTIGATION ON NATURAL FIBER AND RESIN}

Natural fibers applied as composite are mainly divided into the organic matter and the inorganic matter. The plant fiber is the representative organic matter among natural fibers, and inorganic matter is classified into mineral fiber, etc. Natural fibers being dealt with in this study are plant fibers such as flax, hemp, jute, sisal, agave, henequen, coir, etc [1]-[4].

For the eco-friendly structure design, properties of various natural fibers are compared. Firstly, the fiber contents shows that $71 \%$ in flax, $65 \%$ in jute, $72 \%$ in hemp and $69 \%$ in sisal. Through comparison of mechanical strength and stiffness, it is found that the flax fiber has the best properties. Fig. 1 shows the weaving configuration of the flax $2 \mathrm{D}$ fabric. Mechanical properties of representative natural fibers are presented at Table I. Therefore the flax is selected as a natural fiber to be applied to the eco-friendly structure. Moreover, the flax fiber has better vibration absorption behavior, cheaper and easier procurement than other natural fibers. The flax fiber is widely produced in Europe currently, for instance, France occupies $80 \%$ of its supply. Recently the use of flax fiber increases for aircraft door, automobile interior, tennis racket, bicycle frame, table, building structure and mobile phone case, etc.[5].

The resin for natural fiber composite is mainly divided into thermoplastic resin, thermosetting resin and bio resin. Representative thermoplastic resins are polyethylene, polypropylene and polyamide, and the representative thermosetting resins are epoxy, vinyl ester, phenolic, etc. Recently, natural resins have been developed, for instance cashew nut shell oil resin (CNSL) collected from fruit peel of tropical tree as a representative bio resin.

In order to select a proper resin for this study, mechanical properties of polyester, vinyl ester, epoxy and phenolic resin are investigated shown as Table II. Although the phenolic resin has excellent flame resistance, it has a flaw of manufacturing process difficulty. The epoxy resin is widely used for carbon or glass fiber composite as well as for natural fiber composite, but a disadvantage is relatively high price. In this study, the vinyl ester is firstly selected due to cheap price 
even though somewhat low mechanical properties compared to epoxy. However the epoxy is used for comparison with the vinyl ester.

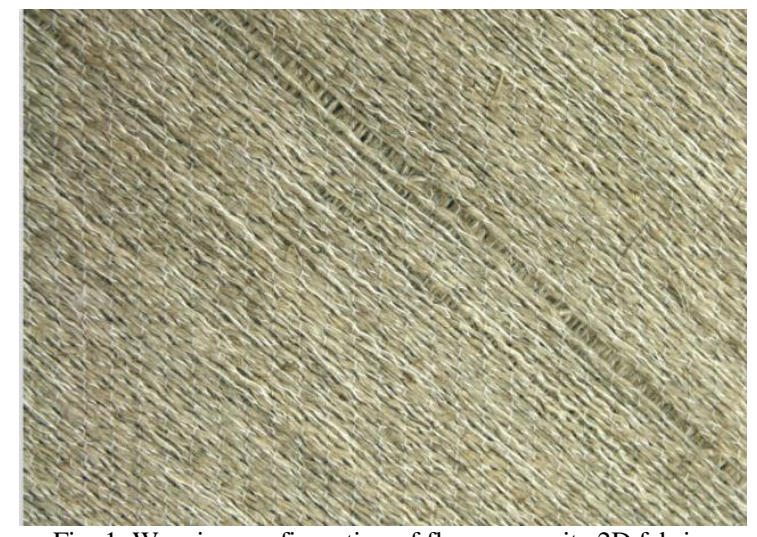

Fig. 1. Weaving configuration of flax composite 2D fabric.

TABLE I: MECHANICAL PROPERTIES OF NATURAL FIBERS

\begin{tabular}{c|c|c|c}
\hline \multicolumn{2}{c|}{ TABLE I: MECHANICAL PROPERTIES OF NATURAL FIBERS } \\
\hline Hemp & $\begin{array}{c}\text { Density } \\
{\left[\mathrm{g} / \mathrm{cm}^{3}\right]}\end{array}$ & $\begin{array}{c}\text { Stiffness } \\
{[\mathrm{GPa}]}\end{array}$ & $\begin{array}{c}\text { Strength } \\
{[\mathrm{MPa}]}\end{array}$ \\
\hline Flax & $1.5-1.6$ & $30-60$ & $300-800$ \\
\hline Jute & $1.3-1.5$ & $50-70$ & $500-900$ \\
\hline Sisal & $1.2-1.4$ & $20-55$ & $200-500$ \\
\hline Cotton & $1.5-1.6$ & $9-22$ & $100-800$ \\
\hline Soft wood & $1.2-1.4$ & $6-10$ & $300-600$ \\
\hline \hline
\end{tabular}

TABLE II: MECHANICAL PROPERTIES OF RESINS

\begin{tabular}{c|c|c|c|c}
\hline \hline Property & Poly esters & $\begin{array}{c}\text { Vinyl } \\
\text { esters }\end{array}$ & Epoxies & Phenolics \\
\hline $\begin{array}{c}\text { Tensile } \\
\text { strength (MPa) }\end{array}$ & $34-105$ & $73-81$ & $55-130$ & $50-60$ \\
\hline $\begin{array}{c}\text { Tensile } \\
\text { modulus (GPa) }\end{array}$ & $2.1-3.5$ & $3-3.5$ & $2.7-4.1$ & $4-7$ \\
\hline $\begin{array}{c}\text { Flexural } \\
\text { strength (MPa) }\end{array}$ & $70-110$ & $130-140$ & $110-150$ & $80-135$ \\
\hline $\begin{array}{c}\text { Flexural } \\
\text { modulus (GPa) }\end{array}$ & $2-4$ & 3 & $3-4$ & $2-4$ \\
\hline $\begin{array}{c}\text { Specific gravity } \\
\text { Cure shrinkage } \\
(\%)\end{array}$ & $1.1-1.4$ & $1.1-1.3$ & $1.2-1.3$ & $1.2-1.3$ \\
\hline \hline
\end{tabular}

\section{VACUUM ASSISTED RTM-LIGHT MANUFACTURING METHOD}

Recently, the resin transfer molding (RTM) process method is emphasized for curing the large complicated shape composite structures. The RTM is a method of injecting the resin into the preform enclosed by the moulds. The preform is made of dry fibers, fabrics or mats prior to injecting the resin. If the resin injection pressure is low of $0.7 \mathrm{MPa}$ while low viscosity and high molecule resin is used. The injection device and the mold are simple as well as low cost compared to high pressure injection device or the mould.

This study adopts the VARTML (Vacuum Assisted RTM-Light) manufacturing process that the RTM uses vacuum circumstance to remove gas or air from the perform and the light mold due to low press injection. The VARTML method is slightly different from the RTM that consists of solid stiff moulds. It uses a solid stiff mould for one side while a flexible mould with vacuum for the other side. By using both the positive pressure and vacuum pressure, the resin filling time can be shorten less than the gelling time as well the fiber volume fraction is improved by reducing voids in the preform. Therefore the VARTML process is an advanced composite manufacturing method that allows much higher quality product than the hand lay-up process, and less manufacturing cost compared to the RTM and the autoclave method.

\section{MANUFACTURING OF SPECIMEN USING VARTML}

In this study, the flax/vinyl ester composite specimens are manufactured using the VARTML method, and their mechanical properties are evaluated. The flax unidirectional fibers and 2D fabrics $\left(600 \mathrm{~g} / \mathrm{m}^{2}\right)$ are purchased from Composite Evolution company in Europe. The KRF-1031 vinyl ester resin is purchased from CCP Composite Company. The panels are firstly manufactured using the VARTML method. The specimen size cut out from the panel follows ASTM standards.

To improve the strength of the flax fiber composites, a special treatment to remove the remaining moisture must be needed. Therefore the fibers are laminated on the panel moulds after drying in oven for 15 minutes at $110{ }^{\circ} \mathrm{C}$ temperature. The curing temperature of $80^{\circ} \mathrm{C}$ is maintained for 2 hours, then the post curing temperature of $120^{\circ} \mathrm{C}$ is maintained for an hour. Fig. 2 shows the manufactured panel for specimen.

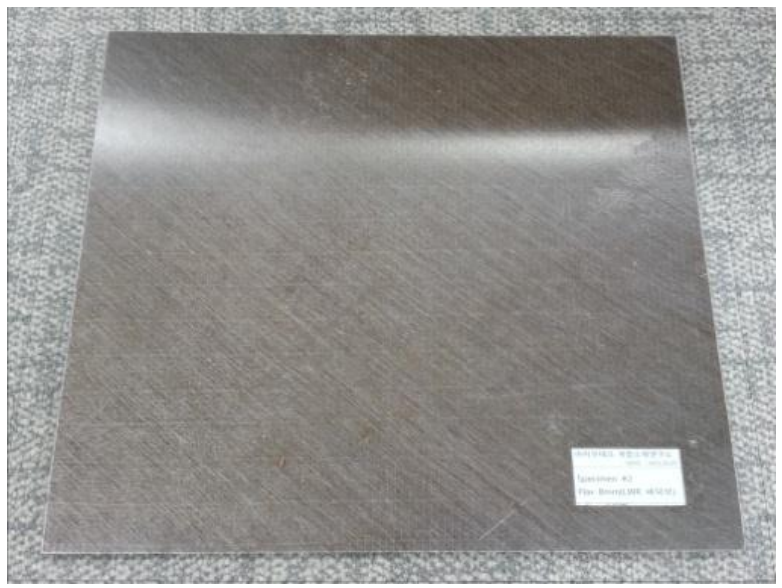

Fig. 2. The manufactured panel for specimen.

\section{REVIEW ON PREVIOUS STUdies REGARding FLAX COMPOSITES}

Prior to testing mechanical properties of flax specimens using the VARTML, the mechanical properties of the flax/thermoset resin composite specimens presented at previous studies are reviewed.

According to Oksman K.'s experimental test results of the 
UD flax/epoxy specimen manufactured by the RTM method, the fiber volume fraction was $21 \sim 47 \%$, the fiber direction elastic modulus was $15 \sim 39 \mathrm{GPa}$, and the tensile strength was 132 280MPa [6].

Van de Weyenberg et al. reported the test results of the UD flax/epoxy fiber that the fiber volume fraction was $50 \%$, the fiber direction elastic modulus was $32 \mathrm{GPa}$ and the tensile strength of $268 \mathrm{MPa}$. In addition, the bending strength change due to the surface treatment to remove the moisture from fiber was investigated. After the surface treatment by 1 3\% sodium hydroxide, then the autoclave curing was performed. Through this treatment, it was found that the fiber volume fraction was $40 \%$ and the bending strength was improved [7].

Hughes et al. evaluated the mechanical properties of the UD flax fiber/vinyl ester resin composite and the flax fabric /vinyl ester resin composite manufactured using VARTM method. In case of the UD flax composite, it was found that the fiber volume fraction and the tensile strength are $25 \%$ and 122.4 MPa, respectively. In case of flax fabric flax composite, it was found that the fiber volume fraction and the tensile strength are $25 \%$ and $62.0 \mathrm{MPa}$, respectively [8].

\section{MEChaniCAL PRopertiES OF FlaX/VINYL Ester SPECIMEN}

In order to compare with the mechanical properties of flax fiber evaluated through previous studies, this study evaluates the mechanical properties of the UD flax /vinyl ester specimen and the flax fabric/vinyl ester specimen manufactured using the VARTML method. For the different type tests such as tension, compression, flexure and in-plane-shear, 5 specimens per a type test are manufactured to obtain the mean value. Specimen tests are performed by both JNTP (Jeonnam Technopark, Korea) and AMRC (Advanced Manufacturing Research Centre with Boeing, UK). The specimen tests follow the ASTM standards(D3039, D6641, D790, D5379).

TABLE III: MECHANICAL PROPERTIES OF UD FLAX/VINYL ESTER SPESIMEN (FIBER VOLUME FRACTION: 35\%)

\begin{tabular}{c|c|c}
\hline \hline Test Institute & \multicolumn{2}{|c}{ Jeonnam Technopark } \\
\hline Test type & Strength (MPa) & Modulus (GPa) \\
\hline Tension & 157.5 & 10.4 \\
\hline Compression & 102.9 & 19.4 \\
\hline Flexure & 188.0 & 9.7 \\
\hline In-plane-shear & 26.24 & 3.8 \\
\hline \hline
\end{tabular}

The specimen test results conducted by JNTP shows that the fiber volume fraction of the UD flax fiber composite is $35 \%$ and the fiber volume fraction of the 2-D flax fabric composite is $34 \%$. These volume fractions are higher than the volume fractions of $25 \%$ of Hughes et al.'s specimens. In case of comparison of tensile strength, the tensile strengths of the UD flax composite and the 2-D flax fabric composite manufactured by JNTP are $157.5 \mathrm{MPa}$ and $76.7 \mathrm{MPa}$, respectively which are much higher strength than the reference strengths of $122.4 \mathrm{MPa}$ and $62.0 \mathrm{MPa}$. Table III shows the mechanical properties of the UD specimens and Table IV shows the mechanical properties of 2-D fabric specimen. Another specimen tests of the UD flax fiber//vinyl ester are performed by AMRC to compare with JNTP's test results. The AMRC test results show much higher strength values than JNTP test results due to the moisture removing treatment and the post curing treatment. Table $\mathrm{V}$ shows the AMRC specimen test result such as tensile strength of 227.2MPa with fiber volume fraction of $51 \%$.

TABLE IV: MECHANICAL PROPERTIES OF 2-D FLAX/VINYL ESTER SPESIMEN (FIBER VOLUME FRACTION: $34 \%$ )

\begin{tabular}{c|c|c}
\hline \hline Test Institute & \multicolumn{2}{|c}{ Jeonnam Technopark } \\
\hline Test type & Strength $(\mathrm{MPa})$ & Modulus $(\mathrm{GPa})$ \\
\hline Tension & 76.7 & 9.1 \\
\hline Compression & 72.8 & 6.2 \\
\hline Flexure & 108.7 & 6.7 \\
\hline In Plane Shear & 36.1 & 1.6 \\
\hline \hline
\end{tabular}

TABLE V: MECHANICAL PROPERTIES OF UD FLAX/VINYL ESTER SPESIMEN (FIBER VOLUME FRACTION: 51\%)

\begin{tabular}{c|c|c}
\hline & \multicolumn{2}{|c}{$\begin{array}{c}\text { Boeing } \\
\text { Test Institute }\end{array}$} \\
\hline Test type & Strength (MPa) & Modulus GPa) \\
\hline Tension & 227.2 & 22.3 \\
\hline Compression & 124.4 & 15.5 \\
\hline Flexure & 252.1 & 14.3 \\
\hline Inter Laminar Shear & 27.6 & - \\
\hline \hline
\end{tabular}
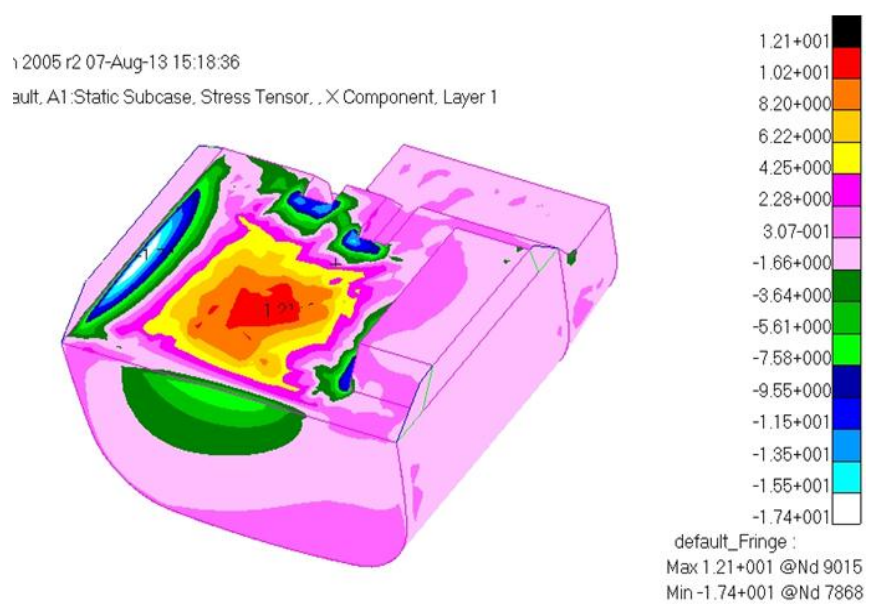

Fig. 3. Stress contour of agricultural chemical tank

-1.74+001@Nd 7868

\section{Structural DESIGN CONSIDERING OF RESIN FLOW SIMULATION OF VARTML}

After investigation on mechanical properties of flax/vinyl ester composite, the design of eco-friendly structure using flax/vinyl ester was performed. The selected target structure 
is chemical storage tank for agricultural vehicle. In order to evaluate the structural design results of chemical storage tank the structural analysis was performed by the finite element method using MSC. Nastran. According to stress analysis results, the maximum compressive stress was $17.4 \mathrm{MPa}$ and tensile stress was $12.1 \mathrm{MPa}$. Therefore, structural safety of design results was confirmed. The buckling analysis was done by the same FEM model. The minimum buckling load factor was 7.3 and was confirmed safe from buckling. Through the structural analyses, it is confirmed that the designed chemical storage tank using natural flax composite is acceptable for structural safety and stability. Fig. 3 shows stress contour of agricultural chemical tank by FEM analysis.

After structural design and analysis, the resin flow analysis of VARTML manufacturing method was performed. The flow analysis of flax/vinyl ester composite tank was performed to confirm the manufacturing possibility using VARTML and to predict of resin flow filling time and confirm no dry-patch. The resin flow analysis was performed using the RTM-Worx FEM flow simulation solver. The permeability coefficient data is important for resin flow analysis. Therefore the design and manufacture of a permeability test rig and subsequent test were performed before resin flow simulation.

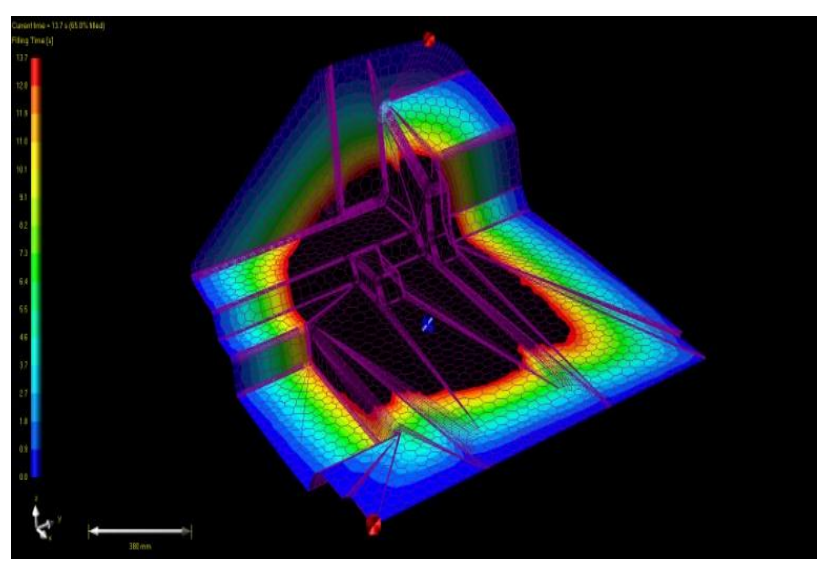

Fig. 4. Resin flow analysis result of lower part.

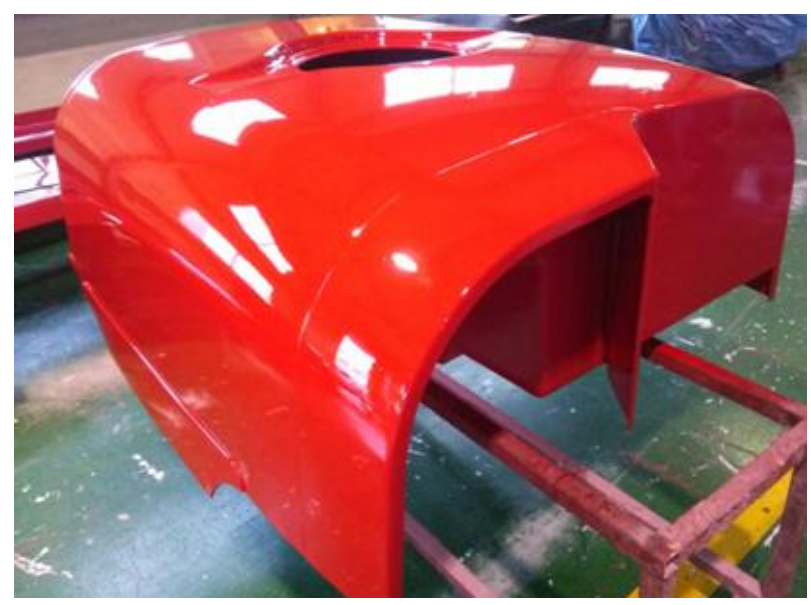

Fig. 5. Manufactured agricultural chemical tank.

The resin flow analysis was performed based on tested permeability coefficient. The modeling using thin shell element was conducted by RTM-Worx software. Each flow analysis of upper part and lower part were investigated. Injection pressure of first analysis of upper part is 1.6bar. Vacuum pressure is 1 bar. According to flow analysis results, the resin filling time was $3810 \mathrm{sec}$. Because the filling time is greater than resin gel time $3000 \mathrm{sec}$, resin injection condition must be changed. Therefore, injection pressure must increase. Finally, resin injection pressure increases as 3bar. According to second flow analysis results at 3 bar injection pressure condition, the resin filling time was $2420 \mathrm{sec}$. In case of lower part, injection pressure is $1.6 \mathrm{bar}$. Vacuum pressure is $1 \mathrm{bar}$. According to flow analysis results of lower part, the resin filling time was $1780 \mathrm{sec}$. Fig. 4 shows resin flow analysis result of upper part. The resin flow simulation results of upper and lower parts were compared with the result of resin injection test. From the experimental results, the tested injection times are well agreed with the analytical results.

In this work, after investigation on structural analysis and resin flow simulation results of chemical storage tank, the prototype tank was manufactured using flax/vinyl ester. In order to manufacture the prototype tank, the VARTM method is adopted. Fig. 5 shows manufactured agricultural chemical tank using flax/vinyl ester. Finally, in order to evaluate the designed tank, the performance test was performed. According to the performance evaluation result, structural safety was confirmed.

\section{CONCLUSION}

In this study, an investigation on mechanical properties of flax/vinyl ester natural fiber composite is performed as a precedent study on the design of eco-friendly structure using flax/vinyl ester composite. The Vacuum Assisted Resin Transfer Molding-Light (VARTML) manufacturing method is adopted for manufacturing the flax fiber composite specimen. The mechanical properties of the manufactured flax composites specimens are compared with flax composite data cited from some references. The experimental data show that the flax/vinyl ester composites using the proposed VARTML manufacturing method have much better mechanical properties than the reference test results. Based on this, structural design of chemical storage tank for agricultural vehicle was performed using flax/vinyl ester. After structural design and analysis, the resin flow analysis of VARTML manufacturing method was performed. Through the structural analyses, it is confirmed that the designed chemical storage tank is acceptable for structural safety and stability.

\section{ACKNOWLEDGMENT}

This study was supported by research funds from Gwangju Innopolis Global Collaboration Project (2012D002) and Howon University Research Funds.

\section{REFERENCES}

[1] Y. J. Xie, C. A. S. Hill, Z. F. Xiao, H. Militz, and C. Mai, "Silane coupling agents used for natural fiber/polymer composites: a review," Composites Part A: Applied Science and Manufacturing, vol. 41, pp. 806-819, 2010.

[2] D. Puglia, A. Iannoni, J. M. Kenny, C. Santulli, F. Sarasini, and T. Valente "Thermal and mechanical behavior of phormium tenax reinforced polypropylene composite," in Proc. ECCM-15 Conference, pp.1-7, Venice, 2012.

[3] L. Q. N. Tran, C. Fuentes, C. Dupont-Gillain, A. Van Vuure, and I Verpoest, "Coir fibre composites: from fibre properties to interfacial adhesion and mechanical properties of composites," in Proc. ECCM-15 Conference, pp. 1-6, Venice, 2012. 
[4] M. Gomina, Flax and hemp composites applications. Jec composites, France, 2012, pp. 141-162.

[5] J. Mussig and M. Hughes, Flax and hemp fibers: anatural solution for the composite industry, Jec Composites, France, 2012, pp. 40-41.

[6] K. Oksman, "High quality flax fibre composites manufactured by the resin transfer moulding process," Journal of Reinforced Plastics and Composites, vol. 20, no. 7, pp. 621-627, May 2001.

[7] I. V. de Weyenberg, I. C. Truong, B. Vangrimde, and I. Verpoest, "Improving the properties of UD flax fibre reinforced composites by applying an alkaline fibre treatment," Composites Part A: Applied Science and Manufacturing, vol. 37, issue 9, pp. 1368-1376, Sep. 2006.

[8] M. Hughes, J. Carpenter, and C. Hill, "Deformation and fracture behavior of flax fibre reinforced thermosetting polymer matrix composites," Journal of Material Science, vol. 42, issue 7, pp. 2499-2511, April 2007.

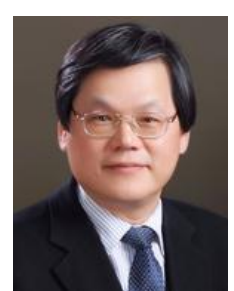

Changduk Kong graduated with a BSc in aerospace engineering from the Korea Aerospace University and $\mathrm{a} \mathrm{PhD}$ in aerospace engineering from the Osaka Prefecture University, Japan. He was appointed as a professor in 1994 in the Department of Aerospace Engineering at Chosun University and was Dean of the School of Aerospace and Naval Architecture Engineering in 1999/2005-2006 and the dean of the Facility Management Office at Chosun University, 2011-2012.

He has contributed greatly to the development of aerospace engineering in Korea, primarily through his roles as the president of SASE (The Society for Aerospace System Engineering) in 2013-2014, President of ICRC (International Collaboration Research Centre in Natural Composites, Chosun University) since 2012, former president of KSAS (The Korean Society for Aeronautical and Space Sciences, 2012), former president of KSPE (The Korean Society of Propulsion Engineers, 2007-2008), ex-chair of Cycle Innovation-IGTI-ASME between 2009 and 2011, former President of RIME (Research Institute of Mechanical Engineering-Chosun University, 2006-2008) and former head of the Aero-Propulsion Division of ADD (Agency for Defence Development,1978-1994), first lieutenant of ROKAF(Republic of Korea Air Forces, 1974-1978). He received the Korean National Decoration in Science for his scientific contribution to Korean aerospace development.

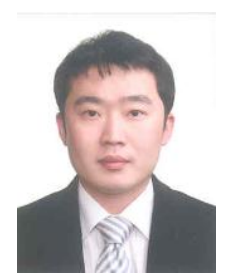

Hyunbum Park graduated with a BSc, MSc, PhD in aerospace engineering from the Chousn University, Rep. of Korea. He was appointed as a professor in 2012 in the Department of Defense \& Science Technology, Aeronautics at Howon University. He is a member of The Society for Aerospace System Engineering.

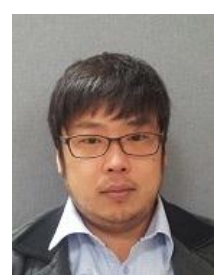

Haseung Lee graduated with a BSc, MSc in aerospace engineering from the Chousn University, Rep. of Korea. He is the $\mathrm{PhD}$ candidate in aerospace engineering from the Chousn University. He is a member of The Society for Aerospace System Engineering.

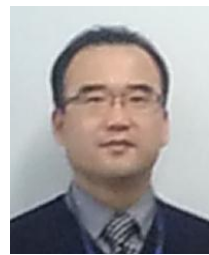

Jeongwhan Lee graduated with a BSc, MSc in aerospace engineering from the Chousn University, Rep. of Korea and a PhD in aerospace engineering from the Imperial College London, UK. He is a member of The Society for Aerospace System Engineering and the president of The Korean Scientists and Engineering Association in The UK. 